\title{
Lectura sociolingüística de dos novelas para el tiempo abatido: La sierra en Ilamas y Siempre quedará París'
}

\author{
Sociolinguistic Reading of Two Novels for Depressive Times: \\ La sierra en llamas y Siempre quedará París \\ ANTONIO DANIEL FUENTES GONZÁLEZ \\ Universidad de Almería \\ España \\ dfuentes@ual.es
}

(Recibido: 26-II-2OI4;

aceptado: $\mathrm{IO}^{-\mathrm{O} 3-2 \mathrm{O} 5}$ )

Resumen. Durante los últimos años, los muros amnésicos del franquismo y de la transición están siendo agrietados por la necesidad de alivio de la memoria democrática, inundando un terreno de lucha social que atrae también a la literatura. En este trabajo se analizan sociolingüísticamente La sierra en llamas (1952) y Siempre quedará París (2005). Desde diferentes perspectivas y con un discurso y aparato narrativo distintos, ambas novelas rememoran la guerrilla antifranquista de mediados del siglo $X X$, uno de los episodios del que poco se ha querido saber porque no concita reconocimiento. Parece un trauma que ha desembocado en la culpa colectiva, sin responsabilidad, pero que los renglones de la literatura tratan -en estos dos casos- como brazo simbólico-militar de un tipo de franquismo desplazado que barrunta su derrota desde laVictoria - vencedores vencidos los denomina Núñez Seixas (2005)- o como batalla por sobrevivir a la debacle y por sobreponerse al abandono.

Palabras clave: Lectura sociolingüística; memoria democrática; guerrilla antifranquista; novela española; variación gentilicia.
Abstract. Over the past few years, the amnesic wall fronts of Franco's regime and of the Spanish transition are being cracked by a need for pain relief of the democratic heritage, which is deluging one strand of social struggle that has an effect on literature. In this paper, we carefully analyse, from a sociolinguistic approach, La sierra en llamas (1952) and Siempre quedará París (2005). From different viewpoints and quite different allocutions and narrative apparatus, both novels recall anti-Francoist guerrillas dating from the mid-20th century. So far, this is a not seriously considered episode, since it is rather underestimated. It seems to be a trauma that has culminated in the practice of collective guilt, without any responsibility, but which is dealt with by literature. In these two titles one can appreciate a symbolic military arm tied to some kind of displaced Francoism that looks forward to its defeat from victory. Núñez Seixas, (2005) calls them «The defeated victors» and could be considered as a crossroads fight to ride out the downturn in order to move past dereliction.

Keywords: Sociolinguistic Reading; democratic heritage; anti-Francoist guerrilla; Spanish novel; family name variation.

\footnotetext{
${ }^{\text {I }}$ Para citar este artículo: Fuentes González, Antonio Daniel (20I5). Lectura sociolingüística de dos novelas para el tiempo abatido: La sierra en llamas y Siempre quedará París. Alabe 11. [www.revistaalabe.com] 


\section{I - Introducción: la memoria del tiempo abatido}

Durante los últimos años, la recuperación de la memoria histórica ${ }^{2}$ emerge en primera línea política frente a la utilidad del olvido. Aquí se analizarán sociolingüísticamente dos novelas sobre uno de los episodios olvidados de esta memoria histórica, el de la guerrilla antifranquista ${ }^{3}$, La sierra en llamas (en adelante LSL), de Ángel Ruiz Ayúcar, y Siempre quedará París (SQP), de Ramón Acín Fanlo.

Las memorias -con sus olvidos- son plurales, política, cultural y temáticamente, verificando nuevas dimensiones en el palimpsesto de la memoria colectiva. La literatura viene -casi siempre desde los márgenes de la Historia- a inyectar nuevos flujos en las arterias del reconocimiento histórico, aunque, como se comprobará, tiene como rompeolas un criterio historiográfico de historia buena como buena para nosotros (Hobsbawn, 1998): nuestro país, nuestra causa o sencillamente nuestra satisfacción emocional.

Hasta el comienzo de los años 6o, la España franquista en paz se vio retada por una resistencia armada posterior a abril de I939. Marco (2006: 285), no sin ironía ante otras interpretaciones, sugiere que los cuarenta y cincuenta podrían denominarse período durmiente, un remanso apenas atendido por la historiografía sobre el período. Los hechos históricos indican lo contrario. Se entiende así que se haya rotulado la resistencia armada antifranquista como el último frente (Aróstegui y Marco, 2008). Serrano (2OOI) también advierte que otra historiografía divulga desde hace tiempo una doble ola revisionista, equilibrando culpas, bloqueando enfoques más veraces y democráticos con el pasado y continuando con una historia a medida de los vencedores de la guerra. Domingo (2002: 20 y ss.) diagnostica que a aquellos supervivientes se les sepultó en el olvido, lo que exige una memoria no tanto oral, que sí ${ }^{4}$, como coral, que tenga en cuenta a las milicias pasivas, a la mujer, víctima por antonomasia de la posguerra; requiere también de la memoria silenciada.

Importa ahora señalar que hay bien coordinados dos diques de contención contramemorísticos, I) el de la Transición, sustentado en 2) el de II República-Guerra Civil. Pérez Serrano (2004) plantea que las identidades franquistas se basaron en el olvido y la manipulación del recuerdo de la República, animada por una semántica de II República como causa y dictadura franquista como consecuencia, alentándose con ello la desaparición deamboscapítuloshistóricos, puesrecordabanlaculpacolectiva. Esentonces una genuina memorización del olvido, valiosa para rehacer el Estado, sin personajes y episodios inoportunos e irreconciliables. La Transición como tiempo desambiguador

\footnotetext{
${ }^{2}$ Cfr. Aróstegui (2004) para observar la problemática de este sintagma.

3 No es un estudio ex novo. Como botón de muestra, véase la bibliografía de Bertrand de Muñoz (I986) o -más recientemente- los más de 225 títulos de ficción y 570 de no ficción compilados por Moreno Gómez y Romero Navas (2012) en su Bibliografía de Guerrilla. Publicaciones sobre el fenómeno del maquis antifranquista. La pluralidad de contribuciones literarias es "tan extensa que para hacerse una idea habría que compilar una bibliografía de sus bibliografías (Potok, 2OI2: 9).”

${ }^{4}$ Aróstegui (2004: 29) aconseja al respecto la consulta de la revista Historia y Fuente Oral (Historia, Antropología $y$ Fuentes Orales).
} 
de España ha pretendido invisibilizar la resistencia guerrillera al identificar perdón con olvido para relatar una hazaña democratizadora como encuentro de todos. El término transición ha sido en todo ello de capital importancia al adaptar su referencia económicomarxista como proceso lento de profundos cambios estructurales (p. ej. transición del esclavismo al feudalismo, transición del feudalismo al capitalismo, ergo, transición de la dictadura a la democracia). El esquema conceptual coste-beneficio como subesquema del de democracia como mercado, soporte de la globalización, ha sido el resultado de esa adaptación de la referencia marxista inicial hasta su pleno funcionamiento como garantía de una sociedad de libre mercado. Antes, en la edificación del otro dique, la retórica bélica de i936 parecía idéntica en los beligerantes (Juliá, 2009), al menos aparentemente, porque unos y otros se describieron mutuamente como enemigos exteriores: un invasor, el moro malo, africano, externo, no peninsular -detectado por Querol Sanz (2OIO) en la literatura española- o el rojo comunista de Rusia. Esa guerra contra el invasor se convertirá en guerra fratricida, tras constantes (re)construcciones nominales según las cambiantes circunstancias para ampliar consensos y agregaciones ideológicas: dentro de la legalidad republicana se pasó de resistencia popular a guerra antifascista, mientras que los sublevados rebeldes comenzaron con el término alzamiento para redescribirse luego como cruzada liberadora del comunismo (Juliá, 2009: 38). Esta nueva exigencia de memoria democrática sacude traumáticamente el tránsito ideológico hacia la denominada "reconciliación nacional" ( no removamos el pasado, adónde vamos a ir con eso, no hay que provocar otra guerra, etc.), probablemente porque aquel tiempo supone un trago difícilmente digerible, para los jerarcas franquistas y para los organizadores de la guerrilla.

Desde la investigación literaria, Sánchez Zapatero (2OIO: 29) realza el deber de memoria de los testigos para evitar deformaciones o eliminaciones. En este debate la literatura es un poderoso fenómeno propositivo del rescate del pasado o del mantenimiento del silencio (Carvalho dos Reis (20I3). Pueden encontrarse fundamentalmente novelas en uno y otro sentido. En España el discurso (meta)literario sobre la memoria se ha focalizado en torno a la llamada Guerra Civil (Winter, 2oo6; Luengo y Cuñado, 2007), sin desatender referencias sobre otros periodos históricos, sea la emigración española desde I96o hacia diferentes países europeos (Ruiz Sánchez, 2007), sea sobre los años de posguerra, fundamentalmente recuperados 5 a partir de la resistencia antifranquista (Izquierdo, 2OOI y 2002; Tyras, 2007; Faix, 2009; Sánchez Zapatero, 2OII; Moreno-Nuño, 2OI2; Bultheel, 2OI2).

\footnotetext{
${ }^{5}$ Domingo (2002: 336-337) recoge testimonios de los propios protagonistas desde ese limbo de los recuerdos: "No me pesa haber estado en la guerrilla [...] Pero a veces te pones a pensar, ¿es verdad o no que ha existido eso?”
} 


\section{2- El potencial del encuentro entre sociolingüística y literatura: ¿qué es una lectura sociolingüística?}

La literatura configuraba los materiales indiscutidos del objeto de estudio sociolingüístico, más identificado hoy desde la óptica anglosajona (y en su aérea de influencia) con un saber cuantitativo que mide fenómenos lingüísticos según variables sociales externas. Al lado de esta hegemonía académica bibliográficamente establecida, conviene recordar a autores como Voloshinov (I929[I992]) para asumir que la continua transformación social viene coimplicada con la actividad lingüística, de manera que sociolingüísticamente se persiguen y consiguen procesos de hegemonía social en continua circulación de sentidos engarzada con/en contextos situacionales. Con esta versatilidad teórica, el lenguaje sería tanto proceso como sistema, lo que vale decir que se revitalizaría esa vocación fundacional atenta a trabajos teórico-prácticos alrededor de los problemas del lenguaje (socio-, pragma- y psicolingüística), de teorías ideológicas, de estudios literarios o como soporte epistemológico de la amplia gama de análisis discursivos.

En esa línea, la lectura sociolingüística es un conjunto de prácticas orientadas para desentrañar realidades y procesos sociolingüísticos a partir de los que todo texto se produce, se recibe y se lee (Fuentes González, 2OI5a). Puede afirmarse, por tanto, que todo texto es susceptible de lecturas sociolingüísticas, dada la naturaleza social del lenguaje. No cabe duda, empero, que esa preferencia por lo literario remite a la tradición filológica, casa común tanto de estudios específicamente literarios, como de teorías lingüísticas que han subrayado la esencia dinámica, situacional, discursiva y colectiva del uso lingüístico.

Reavivando la onda larga de Voloshinov, Fowler (I988) y Lambert, Meylaerts y Borden (2005) insisten en la poco transitada conexión entre sociolingüística y teorías literarias y discursivas modernas, que, sin embargo, han generado, por ponervarios casos, un completísimo estudio sociolingüístico del diálogo en la literaturabrasileña(Preti, I975), brillantes trabajos sobre partidas de nacimiento, reglamentos de instalaciones deportivas (Fowler et al. [I979]I983), o sobre legislación europea (Fairclough, 200o), reabriendo con ello el paisaje disciplinar sociolingüístico, quizá reducido tradicionalmente también por su vocación oralista (Jiménez Cano, 2003: $5_{52}^{2}$ ).

Desde una concepción triádica del signo, Rossi-Landi (i97o) plantea un proceso vinculante de estos tres elementos (cosas, conceptos y palabras) mediante un conjunto denominado representaciones. Como la relación entre signo y referente aparece menos clara, el sentido comienza a deslizarse hacia la incertidumbre, hasta el punto de que causas ilusorias pueden producir efectos reales, ya que a veces tendemos a ser víctimas de nuestras convenciones lingüísticas. El sentido no es traslúcido entre los participantes comunicativos. De ahí que el lenguaje como identificador también se mueva y que en libertad política (o incluso sin ella) pueda transfigurar identidades sin necesidad de cambiar las palabras, animadas por intenciones dinámicas. Ello suele hacerse desde puntos de vista que persiguen objetivos, tanto más naturalizados cuanto 
más hegemónicos, convirtiendo sujetos en objetos (cosificados, objetos conversos), o viceversa. El lenguaje sería en definitiva un trabajo que fluye en un mercado, del que las élites sociales pretenden controlar a) el código y sus modalidades; b) el control del canal y las modalidades de circulación y c) el control de las modalidades de codificacióndescodificación de los mensajes, de modo que ese poder redunda en los mensajes propios, al tiempo que pone en circulación ruidos que bloqueen o impidan la comprensión de los ajenos (García Marcos, I999: I32).

Literariamente todo ello funciona eficazmente incorporando, por ejemplo, personajes unívocos, que trasladan a pie juntillas las intenciones del autor, sin explicar contextualmente su papel de malos, salvajes o alimañas. Ese sentido fijado tiende a parecer inevitable, controlando y ahorrando pensamientos desde una construcción representacional y estableciendo una correlación (muy compleja) entre sistema conceptual y sistema lingüístico. Como se reiterará también en este artículo, así es el caso de la representación franquista de la guerrilla antifranquista, que construyó una imagen bestial, animal, terrorista, de esta organización, legitimando su aniquilación. Pero los sentidos y su negociación son plurales, sociales, resultado de prácticas significantes. Es, como se verá, el caso de bandolero y/o bandido, que también en tiempos han actuado sociolingüísticamente como polos magnéticos de lo asocial y lo supersocial (honor, justicia e igualdad), como recuerdan Álvarez Barrientos y García Mouton (i986).

Hall (I997: 9-I6) localiza varios enfoques representacionales, con su trampas y sus ardides, que deben confrontarse con una comunicación constituyente, convencional y compartida, presente en una clase de 'trabajo' que usa objetos materiales y efectos, proyectando prácticas sociolingüísticas, simultáneamente constantes y contingentes, deslizando o invirtiendo el sentido en coherencia con nuevas interpretaciones. Por ello, los sistemas político-estatales exigen representaciones e inversión simbólica para no ser caducos al poco tiempo. El sistema político fascista necesita representar lo social, lo político, como un ente homogéneo, como defendió Schmitt ([1987]2009) al explicar la actividad política (y la guerrillera) mediante una antinomia: quién es el amigo -homogeneidad pública- y quién el enemigo -heterogeneidad que impide lo colectivo(Schmitt, I963). Desde esa representación, la pluralidad no tiene cabida en lo político, porque la política desaparece, definiendo un apoliticismo identitario que debe combatir al Otro si amenaza su homogeneidad. Es lo que ocurrió contra la guerrilla, mediante la despolitización a ultranza con que la combatió la dictadura de Franco, pues la política amenazaba su apoliticismo fascista.

\section{Las dos novelas: La sierra en llamasy Siempre quedará París}

Ángel Ruiz Ayúcar publica La sierra en llamas ([1952][981 $\left.{ }^{6}\right)$ cuando era teniente de la Guardia Civil. En 2005 Ramón Acín Fanlo, profesor de literatura española y

\footnotetext{
${ }^{6}$ Manejaré la versión digital de la edición de Fuerza Nueva en I98I.
} 
conocido animador a la lectura en Aragón, publica Siempre quedará París. Son novelas poco frecuentadas por los estudios literarios. Narran la época de la resistencia guerrillera antifranquista; LSL la lucha contra esa guerrilla misma y SQP el desahucio de los guerrilleros. Solo he localizado un trabajo sobre SQP (Fatás Cebollada, 20o8), sobre la acción como recurso novelístico.

Debido al tiempo transcurrido y a la versión experiencial del autor, LSL ha sido señalada algo más? Su coordinación discursiva con documentos oficiales de la dictadura franquista le ha dibujado un perfil más testimonial como fuente histórica que como valiosa obra literaria. De hecho, su autor fue protagonista, pues "los hechos, los hombres y el clima social de la época están reflejados con la mayor exactitud de que el autor ha sido capaz, LSL, 4". Domingo (2002: I79) apunta que la jerarquía franquista quiso desmilitarizar el conflicto, para no poner en duda su paz, pero también por la ineficacia del ejército para combatir a los maquis tras la invasión del Valle de Arán. Por ello, encargó la represión básicamente a la Guardia Civil, más sigilosa. Esa contraguerrilla dará lugar a novelas, manuales, memorias o ensayos firmados por significados oficiales, jefes y altos mandos de la Guardia Civil que pugnan por tener un lugar en la historia para legitimar "el heroísmo de la Benemérita y reivindicar su sacrificada y desconocida labor en la posguerra", precisamente por haber vencido al peligro comunista en su Cruzada de Liberación (Marco, 20II: 82-83). La necesidad de este capital simbólico no obedece únicamente a necesidades representacionales hacia el exterior como reducto numantino contra el comunismo (sobreponiéndose así a las desventajas exteriores de ser percibidos como una dictadura fascista), sino también a rivalidades internas que la propia dictadura generó con los años, reducido el papel inicial de la Falange (Núñez Seixas, 2005).

Como técnica analítica me valdré de la extracción textual, defendida por Fowler (I988: I36-I46) y validada por Cruz Piñol (I996) para profundizar en los aspectos cognitivos de la secuencialidad y atención lectoras y su control en forma de extracción, primero, y volcado textual después. Se destacarán los párrafos más significativos, incrustados lo más ágilmente posible dentro del texto principal de este trabajo y se anotará únicamente la página-sin el nombre de la novela- cuando no llame a confusión.

\section{I - La sierra en llamas}

La trama novelística es principalmente una densísima estructura semántica gobernada por el esquema imputacional abnegado heroúsmo de la guardia civil vs. criminalidad de los bandoleros. Con ese andamiaje, la variación gentilicia (o designadores grupales), la exclusión léxica zoomórfica mediante el trasunto metafórico cinegético legitimador de la aniquilación, la figuración hídrica como el peligro contenido en las masas humanas, la lucha por la apropiación ideológica o también la finezza sintáctica

\footnotetext{
7 A modo de ejemplo, cfr. Cardinale (2008), Bertrand de Muñoz (I986), Arroyo-Rodríguez (20ıо) o Moreno-Nuño (2OI2).
} 
como ilegítimo recurso de la dirigencia comunista para ampliarse socialmente, serán recursos lingüístico-narrativos que incluso se harán explícitos en muchos pasajes. Pero sobre todo deben atestiguarse las semejanzas tácticas contra los antagonistas, como la animalización de los héroes contra los bestias criminales, extendiendo un excedente de honorabilidad en el amigo interior frente al enemigo exterior, ya que "sabía que no era capaz de rematar a un herido [...] Era un oficial de la Guardia Civil y no un verdugo ${ }^{8}, 53$. " La conquista de ese honor se hace imitando al enemigo, detallando la lucha mimética, usando las mismas ropas o reciclando incluso las de "bandoleros muertos o apresados", 50.”

El siguiente párrafo promociona los principios tácticos de esta guerra chica, que serán el hilo argumental de LSL:

\begin{abstract}
"a esta gente, después de años en la sierra, si se los consigue apresar, se les propone trabajar a nuestro servicio, y ni uno, fijate bien, ni uno dice que no [....] aquellos que por su actuación o conducta más lo merecen, continúan durante largo tiempo trabajando en las contrapartidas. Como ves la homeopatía aplicada al bandolerismo: «similia similíbus curantur». El procedimiento es viejo. Nosotros, encantados con los resultados, pero reconoce que son peor que lobos rabiosos, que hay que tener mala clase para destrozar, sin la menor vacilación, a los compañeros de lucha, de los que se han separado veinticuatro horas antes [...] Estos son los hombres por los que preguntabas, tus románticos de un ideal, 22.
\end{abstract}

En realidad, se presenta la consecuencia como la causa, operación descrita por Heine y Azuaga (2005: I57) cuando los franquistas buscaban sembrar la discordia, procurar que los guerrilleros se entregasen o se dieran muerte entre sí. Asimismo, Domingo (2002: 24) comenta la conversión temática de los sujetos, cuando los antiguos rebeldes acusan de rebeldes a quienes nunca se rebelaron y solo defendieron la legalidad. A todo ello el protagonista, el teniente de la Guardia Civil Manolo Carmena, antepone un discurso legitimador mediante un concepto político en que las masas humildes, ya depravadas, son marionetas en manos de una inteligencia política que no da la cara, justificando un relato como gozne simbólico de la lucha encargada por el dictador, "contra unos criminales, los chacales de la sierra, 23."

La mímesis se extiende triunfante, pues Manolo “no sólo no había despertado

\footnotetext{
${ }^{8}$ Heine y Azuaga (2005: 153) recuerdan sin embargo la orden de que no hubiese prisioneros.

9 Debían descubrir, por tanto, el valor de señales convenidas, como un chasquido provocado entre dos piedras a fin de reconocerse (Vidal Sales ([202]2O06: II4) o el canto de algunas aves, como el del búho. Sin embargo, la brigadilla, las contrapartidas, compuestas por falangistas, guardias civiles voluntarios, algún policía armada, o gente que quería medrar haciendo el trabajo sucio, vestían como los hombres de la montaña, eran un poco ingenuos en esto, se presentaban con su mono y con su gorra, y su uniforme, como que eran guerrilleros, imitándoles [... PHabía algo que no podían imitar: el olor (Domingo, 2002: III).
} 
recelo, sino que los mandos le apreciaban como comunista sincero y disciplinado", también los mandos de la Benemérita, que acaban tuteándolo ${ }^{\text {Iо }}$ " "primero le abrazaba un jefe de la Guardia Civil [luego] el secretario de una organización clandestina, 56 .”

El cabo Ramiro y el guardia Casas son enérgicos, decididos, fuertes, compactos, astutos, familiares, "pero la sierra tenía veneno [...] Casas preparó emboscadas al bandolero como antes las preparaba al jabalí o al lobo”, también típicas de los capturados arrepentidos, como el Varas, "que seguía al cabo Ramiro con la fidelidad de un perro, 5o." Esa metafórica animalizadora no cesa", pues que "hay que aguantarse y no fumar. Estos tíos tienen vientos como los animales y serían capaces de olerlo, 5."

Cuanto mayor fuese el salvajismo, tanto más necesaria sería la aniquilación. Por ello hay una figuración común sobre lo territorial en que la naturaleza es más campo de caza que de batalla ("a enemigo que se queda, puerta de oro, I6"), pues, de hecho, Vidal Sales ([2002]/2006: 3I) caracterizará a los guerrilleros como los fugitivos del terror, duramente acosados por una jauría de perros salvajes.

LSL insiste en el doble juego de semióticas convergentes de grupos antagónicos para exacerbar lo que normalmente se conoce como la estrategia de la escalada. Los miembros de partidas y contrapartidas (guardias civiles y personal reclutado al efecto) deben asumir el salvajismo al vivir en la sierra, y, sobre todo, deben controlar la verbalidad, pues eran “incapaces de hablar seguido, 64.” Ese descriptivismo en común propicia un acercamiento entre las partes combatientes al disminuir la distancia antagónica inicial en beneficio de toques humanísticos y de comprensión hacia el enemigo (ya derrotado) cuando al final son patentes los problemas internos de "las partidas de bandoleros", adoptando los propios términos guerrilleros (División, guerrillas, partidas, etc.), lo que -entre otras razones- se resolverá con el final del protagonista, Manolo Carmena-teniente y Manolo-infiltrado, castigado al pactar con Dios su propia muerte si mostraba "claudicaciones espirituales, 73." Ese tibio reconocimiento del enemigo, frente a la superficie discursiva que machaconamente lo identifica con el salteador de caminos y la canalla social más común, será fundamental décadas después cuando todos los contendientes sean ninguneados en la partitura de la Historia, pues también esos guardias civiles contraguerrilleros querrán reivindicar su papel de aquellos años.

En todo ese entramado parazoosemiótico, destaca la poca capacidad comunicativa del verdadero guerrillero cuando Arras "se propuso domesticar a estas fieras, convertirlos en miembros útiles a la causa. Les hablaba con frecuencia en términos exaltados y editó con multicopista un periódico al que puso por título «¡Adelante!» [...] Los resultados fueron nulos [...] nadie le hacía caso, 77.” Con ello se marca la descomposición

\footnotetext{
Io Que contrasta con la forma de distancia usted de hijo a padre: "Vamos dentro, usted coge la carabina, yo la escopeta y ya verá usted cómo no pasa ni uno, 5 ”, fragmentos en cualquier caso analizables al trasluz de la teoría sociolingüística del poder y la solidaridad.

II Véase en Domingo (2002:50-5I) cómo las propias condiciones de vida en la sierra imponían la prohibición del jabón, porque la espuma era un indicio y no desaparecía en varios kilómetros río abajo; por ello muchos guerrilleros entrevistados declaran que Olíamos peor que las fieras salvajes [...]No podíamos tener higiene.
} 
político-organizativa de la guerrilla, obligada al caos de la supervivencia: “-Mira, cuando yo actúe con vosotros haré lo que tú mandes [...] Pero cuando la División esté inactiva yo podré dar golpes por mi cuenta sin que nadie me pida explicaciones, 79 , resultado lógico de una estructura narrativa que nutrirá, renglón a renglón, ese esquema amigo vs. enemigo, a partir del que florece siempre la predestinación del éxito de la Guardia Civil como "la consecuencia natural, I6".

La cruzada parece ser la guía vital del protagonista, porque "descentrado aún por la guerra reciente [...] buscó el remedio en hundirse más en la causa, I6”, bien arropado por la teoría política instalada en la metafórica del agua como poder para justificar un gobierno fuerte, fascista (Schmitt, [1987]2009), guiño argumental en boca de "un liberado del dominio rojo" por "una España mejor para todos, I8":

\begin{abstract}
"Las masas incultas [...] son como las aguas de los embalses. Su potencia ciega es una fuente inagotable de energía [...] a la hora del triunfo, nos gustaría que esa masa inculta se volviera repentinamente consciente y disciplinada. Hubiera sido ideal poder utilizarla como un grifo, abriendo y cerrando a nuestro gusto. Pero no pudo ser; y por eso perdimos la guerra, I9.”
\end{abstract}

A pesar de que la masa puede ser más dinámica que involutiva (Maffesoli, 1987), se fortalece así el señalamiento de un enemigo depravado y falsamente político, a partir de una larga exposición de Carmena: "Dejemos por un momento la personalidad de los llamados guerrilleros de la República [...] Secuestran a mujeres o niños, algunos de corta edad, y exigen un rescate por ellos [sigue detallando los crímenes] Estos actos, en cualquier país civilizado, no reciben otro nombre que el de bandidaje, 2I.”

El desarrollo del esqueleto actancial amigo guardia civil vs. enemigo bandolero está sobredeterminado por la planificación lingüística de la dictadura; desde el poder se nombra, se impone (Morant, 2OI4), como prescribe la circular de la DGS del II de abril de $1947^{12}$, apostillada como prohibición expresa del vocablo guerrilla, guerrillero o maquis en beneficio de bandoleros, forajidos o bandolerismo en todos los comunicados externos e internos (Yusta, 2002). LSL prolonga esa circular de 1947, de manera que predomina el uso de bandolero (con más de I5o ocurrencias), en covariación léxica con otras variantes, como bandido, terrorista, criminales o forajido. El contexto predicativo de dichos actores-sujetos señala actividades como el hurto, el robo, el pillaje, el asesinato o la violación (p. ej., "los bandidos la habían violado, I4" o "las reservas de la casa pasaban a los morrales de los bandidos, 80"). Es un designador grupal discutido y defendido varias veces, como ya ha podido comprobarse:

\footnotetext{
I2 Sánchez Cervelló (2003: 74-75) señala que con anterioridad -en telegrama postal núm. i66. Guardia Civil. $2^{\text {a }}$ Zona. Barcelona, de 23 de mayo de $1945^{-}$quedó "terminantemente prohibido designar a las partidas de atracadores que actúan en distintos lugares de la península con el nombre de «huidos», «maquis», «guerrilleros», «rebeldes», etc., que ellos desean ostentar para dar a su actuación aspecto político y militar, por lo tanto, en lo sucesivo, siempre que se designe a estos malhechores se hará con el nombre de bandoleros o atracadores que corresponden a los delitos comunes que cometen". Agradezco al profesor Jorge Marco Carretero esta importante indicación bibliográfica.
} 
“-¡Bandidos, bandidos! [...] ¿Es que no hay en el monte luchadores desinteresados, románticos de un ideal que se juegan la vida como lo harías tú en su caso? [...] Pero no se trata de eso, se trata de bandidos, de asesinos, de criminales vulgares [...] que se venden y se matan unos a otros en cuanto ven algo que ganar en ello [...] Una vez más, como tú mismo has dicho, el hombre inculto, aunque ahora sea un bandido, explotado por los dirigentes, 2I-23."

Ese ordenamiento léxico se relaja ocasionalmente, dejando aparecer el término desaconsejado, ya que "El «Tuerto» tenía menos simpatías, pero se reconocía que era un guerrillero hábil y de procedimientos expeditivos que a muchos gustaban, 8o" o mostraba los peligros del lado positivo que la historicidad polarizada que este gentilicio transmite (Cardinale, 2008), cuando “ "Juanito» se enamoró de ella. La chica sufrió el embrujo de la silueta romántica del bandido generoso, cantada tantas veces por la musa popular, $96 . ”$

Queda apuntado el uso, poco frecuente, de terrorista, reservado para las cúpulas guerrilleras y su ámbito, antes urbano que rural, "sostenidas por organizaciones terroristas, 23 " y orientadas "decididamente hacia el bloque soviético, 25", aunque también en "aquella chica, con su actividad absurda de terrorista, vivía como una teresiana laica, 63 ", o en el titular periodístico urdido para no levantar sospechas del asesinato cometido por Manolo cuando fue descubierto: " "Madrid. -En las primeras horas de la noche de ayer, fuerzas especiales de la Guardia Civil dedicadas a la represión del terrorismo, localizaron en esta capital a dos conocidos atracadores ${ }^{13}, 69$." Pero, como se trata de una contraguerrilla, hay también una indisimulada declaración de intenciones de guerra sucia:

"Hay que dirigir los mayores esfuerzos a su destrucción. Debes tomar con urgencia represalias contra los familiares de sus componentes, en especial de los paisanos voluntarios. Han de llevarse a cabo sin la menor piedad, hasta conseguir por el terror que nadie quiera enrolarse en ellas, 74 ".

El circuito de significación de guerrillero se perfila en varios pasajes, siempre y cuando al autor traslade la perspectiva del infiltrado, que debe afinar la destrucción semántica de los textos guerrilleros que caen en sus manos, sean de Julián o de la Junta Central. Se despliegan entonces percepciones propias del análisis crítico del discurso actual, que detectan recursos lingüísticos para embozar la criminalidad guerrillera. Así, se pondera a los guerrilleros magníficos, pero que "no se preocupan en absoluto del aspecto político de la lucha, 42 ", "unos bestias" que no deben apropiarse "por su cuenta de objetos de valor o de arte" para no dar argumentos “a la violenta campaña propagandista de

\footnotetext{
I3 En la bibliografía y en trabajos docufílmicos son frecuentes titulares de prensa que ocultan deliberadamente la realidad bélica, al objeto de certificar la paz franquista, en España y en el exterior, categorizando como delincuencia tiroteos y encuentros entre fuerzas franquistas y guerrilleras: MALEANTE HERIDO Y CAPTURADO POR LA POLICÍA EN ENERO DE I947, EN LA CALLE SOLARES DE GRANADA. RECIBE TRES DISPAROS DEL TENIENTE PRIETO LOPEZ QUE LE PULVERIZAN LA RODILLA (cfr. para todo ello el documental de I992 de Alfonso Arteseros El movimiento guerrillero en Andalucia. Maquis, 1936 6-1952.
} 
las fuerzas represivas, que se empeñan en presentar como actos de bandidaje las heroicas actuaciones de nuestras guerrillas, 74 ", empeño fracasado en la siguiente página porque "aquella misma noche se le plantaron los guerrilleros [...] Ellos no exponían la vida para que se divirtieran los señoritos de Madrid, 75."

Por otro lado, el gentilicio maquis aparece estrictamente asociado con su origen ${ }^{\mathrm{I} 4}$, pues sus pocas ocurrencias lo hacen dentro del contexto francés: “Arras debe su nombre de guerra por haber luchado en el maquis de Arras, zona francesa, 76 ". "Al pasar a la clandestinidad adoptó aquel nombre; era como un símbolo, 84 ”, pero que de desengaño en desengaño cumple rígidamente las tesis de la Guardia Civil, porque "en vez de guerrilleros románticos, de caballeros andantes de la causa, ídolos del pueblo, encontró unas cuadrillas de forajidos sin más ideal que el robo ni más moral que el egoísmo, 84"; es decir, la caracterización del maquis es una disidencia del bandolerismo, pues “ "Arras» pertenecía al grupo romántico del Partido Comunista. Seguía su doctrina como las normas de una religión, pronto al sacrificio, 76 ."

También se enfatiza el ajedrez político de la guerrilla como genuina característica de los responsables comunistas: "Le interesaba que crearan un problema en el campo para explotarlo con fines políticos; pero ni sus personas, ni sus sentimientos le importaban nada. El hombre desaparecía bajo un seudónimo de guerra ${ }^{15}$, bajo un guarismo.

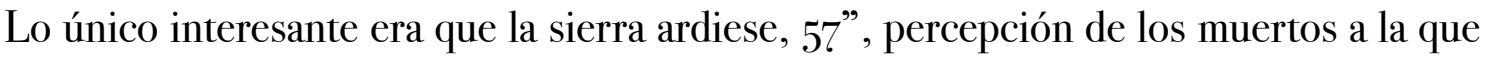
tampoco es ajeno el tablero de las contrapartidas, pues "la muerte del teniente y del cabo en el mismo encuentro hubiera sido demasiada desgracia, $63 \%$.

Observación aparte merecen los apuntes sintáctico-semánticos de la propaganda guerrillera de la Agrupación Centro-Extremadura (Chaves Palacios, 2003) para caracterizar a los falangistas y demás grupos franquistas. El conocimiento de los textos guerrilleros que tenía el teniente Ruiz Ayúcar sobresale explícitamente en su novela:

Dicho llamamiento lo haces extensivo «incluso a los que lucharon durante la guerra civil en campo contrario, con excepción de los falangistas que tengan las manos manchadas de sangre». Esta frase hay que modificarla, ya que podría crear confusiones en el espíritu de nuestros camaradas al hacerles creer que hemos modificado nuestra actitud frente al falangismo. Como la idea que la inspira es acertada, basta con que la cambies en esta forma: «incluso a los que lucharon durante la guerra civil en campo contrario, con excepción de los criminales falangistas». Esta frase satisface todas las tendencias, ya que igual puede interpretarse que se refiere a los falangistas que hayan cometido crímenes, que a todos los falangistas en general, considerados como criminales por el mero hecho de serlo, 74."

\footnotetext{
${ }^{\text {I4 }}$ Perea Delgado (2OI2) destaca su carácter inusual en las sierras gaditanas, frente a expresiones mucho más habituales como los de la sierra o la guerra chica.

I5 Un aspecto sociolingüístico gentilicio que la bibliografía historiográfica no ha pasado por alto es el de los apodos de guerra (Marco, 2OI2). Suelen ser imposiciones nominales que reidentifican a la persona en su papel de miembro, y solo como miembro, de organizaciones que deben camuflarse; el papel del apodo es fundamental también en LSL $(22,26)$, hasta el punto de que el protagonista es descubierto porque su alias, Manolo, coincide con su verdadero nombre, Manolo (Carmena), nombre con el que lo saludan unos compañeros militares en Madrid.
} 
El autor pretende denunciar la ampliación política comunista para ganar apoyos, operación terminantemente aplicada por la contraguerrilla en sentido contrario para envilecer a propósito toda actividad guerrillera, legitimando su aniquilación, casi podría decirse en el sentido del significado de la sexta acepción físico-tecnolectal del DRAE (Dicho de una partícula elemental: Reaccionar con su antipartícula, de forma que desaparecen ambas para convertirse en radiación electromagnética), puesto que esa antipartícula es la creación de las contrapartidas guerrilleras, único procedimiento que empezó a debilitar a la resistencia antifranquista. La aniquilación como estrategia militar parece mutua, tenuamente, porque en el texto de LSL las ocurrencias de la aniquilación obligan a que la Guardia Civil aniquile a las partidas (cfr. las páginas 22, 4I, 50, 55, 63, 86, 88, 94), con la salvedad de la propaganda guerrillera, que llama también a la aniquilación, cuando menos de "grupos reducidos de guardias, 74 ".

En LSL, como apropiación ideológica, se asalta el patriotismo, bien común por el que se luchaba en los 5 o. El lector actual puede sorprenderse al comprobar el uso abundante de patriota por parte de la guerrilla antifranquista, sobre todo porque todavía hoy tiene uso aquello de bando nacional, los nacionales o el Dios, Patria, Justicia como identificadores de los sublevados y rebeldes contra la República. En LSL se aprecia la distribución de patriotas cuando pertenece al entorno de la guerrilla antifranquista (p. ej. "que intentara recobrar el prestigio de la organización y el afecto de los patriotas progresivos. [...] Lanzaba órdenes con multicopista [...] a los católicos patriotas [...] e incluso a los "guardias civiles honrados», 42 "), pero nombre colectivo abstracto desde la perspectiva del protagonista: "no han podido doblegar nuestra fuerza de gigantes, ni torcer el camino de la defensa de los intereses de la Patria, 46 " o "Tengo la seguridad de que tan pronto comprenda la verdad podrá compensar a la Patria del daño que por su ceguera le haya hecho, 95."

Estas coincidencias parciales pueden explicarse mediante la figura de la herra-

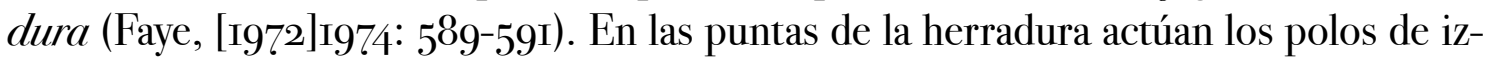
quierda y de derecha, sin centro, saturando la idea de patria. Por esa razón los textos guerrilleros usan profusamente también el adjetivo nacional, patriota o español, pero para construir un concepto de nación como república y no como reserva espiritual. Tampoco es un recurso lingüístico-discursivo genuino. Pêcheux ([I982]I990: II) detecta que la eficacia concreta de las abstracciones es propia del uso lingüístico, visibles precisamente en desplazamientos y disfraces representacionales, animados por una barrera social, invisible, móvil, resistente y elástica, sensible a las relaciones de fuerza. Las mismas palabras o expresiones de una misma lengua no tienen siempre el mismo sentido. Por ello es sorprendente pero no contradictorio que, como formaciones discursivas inscritas en procesos ideológicos, se cosifiquen términos nobles (libertad, orden, justicia, patria, nación, etc.), siendo simultáneamente idénticos y antagonistas.

Por eso quizá también la palabra es realidad y deseo. El final del texto narra los estertores propagandísticos, en el momento en que "Arras se había desahogado. Decepcionado por la triste realidad había hecho surgir de la multicopista un ejército guerrillero 
nuevo, donde todo ocurría según los ensueños de su fantasía, 9o", desahogo que actúa como espoleta de un final en que la Guardia Civil ofrece un pacto de honor, solo a los verdaderos guerrilleros:

Los ojos de «Arras» se humedecieron [...] A un lado estaban el «Cuervo», el «Tropezón», las «Cuadrillas de la guita», una pandilla de salteadores y asesinos sin ideales, y tras ellos, en los seguros refugios del extranjero, el puñado de dirigentes, que se servían ahora de estos miserables como en otro tiempo se habían servido de las masas excitadas, a las que luego abandonaron en la derrota. Al otro lado estaban el orden, la paz, unos ideales capaces de producir hombres como Manolo, que le tendía la mano desde la tumba [...] En una curva de la carretera el coche en que viajaban se cruzó con una pareja de la Guardia Civil. Al ver la matrícula, los guardias saludaron. Después reanudaron su marcha, los fusiles colgados, los ojos clavados en el horizonte, el paso pausado y firme. Marchaban inexorables, como el destino, IO2.”

\section{2 - Siempre quedará París}

El título de SQP evoca la capital francesa como triunfo contra el nazifascismo (agosto de 1944), en el que tuvieron marcado protagonismo guerrilleros exiliados españoles, aunque la narración transcurre todavía más en el monte ${ }^{16}$, evocado en la portada, cuyo fondo es un conocido pico pirenaico ante el que optimistas guerrilleros marchan ya por el Valle de Arán. Podría ser una novela sobre el doble olvido, pues Gaspar Celaya (2OI2: 2) "lamenta que la participación española en la Resistencia francesa haya permanecido durante mucho tiempo evacuada de la memoria colectiva, tanto francesa, como española”.

Más elaborada literariamente que LSL, y más que una hipótesis corroborada, SQP representa a mi modo de ver una lucha por la memoria de la duda, pero también de la esperanza, a pesar del entierro provisional de los ideales. Gran parte de la trama es un homenaje a unos luchadores que -resignados al ser abandonados por su cúpula política ${ }^{17}$ aceptan que "en la guerra, la marea siempre acaba por no dejar ver la pesca, 24." Las operaciones lingüístico-textuales más notables contextualizan un orden sin estado; la praxis política en la sierra dentro de una conciencia de resistencia ante la intensa insistencia del enemigo; la descripción del silencio, entronizado desde la imposición para convertirse

\footnotetext{
${ }^{\text {I6 }}$ Denominación más habitual en el norte peninsular, según Domingo (2002: 27I-272); por las sierras de Andalucía se denominaba la guerra chica, mientras que en otras zonas, sobre todo del norte, se les conocía como los del Monte, en Andalucía al final se les llamaría los de la Sierra, predominantemente (Perea Delgado, 2OI2), también con la variante gente (de) la sierra (Fuentes González, 20I5).

${ }^{17}$ En este sentido, Domingo (2002) recoge varios testimonios: "El Partido Comunista nos había ofrecido el oro y el moro pero nos dejó abandonados, IO2" o "Hemos hecho muchas tonterías, éramos como talibanes, muy dogmáticos, todavía nosotros que éramos jóvenes, pero los que ya llevaban unos años, los que ya sabían y tenían estudios, podían haber acelerado el fin de la guerrilla, no tenía va sentido a qué nos hacían subir al monte, I66." Más templada es la referencia de Ortiz Mateos (2OI3: 338): “En 1948, tras una reunión celebrada en Moscú con Stalin, a la que asistieron Dolores Ibárruri, Francisco Antón y Santiago Carrillo, el PCE adopta un cambio de táctica, abogando por el trabajo político en el seno de las organizaciones legales de masas. Lo que no supuso «desmantelar» las guerrillas, sino la asunción por éstas de nuevas tareas."
} 
en conquista, práctica orgánica, funcionando más como unificador ${ }^{18}$; la evocación del lenguaje y del antilenguaje en tensión con la obligada visibilidad de la política; la acomodación semántica; la apropiación ideológica; el lenguaje quebrado de la memoria-olvido como elección; y en planos más concretos, las hablas interlingüísticas de los maquis o la función unificadora y reconfortante de las paremias. En definitiva, el bosquejo vivo de una segregación que determina el ser conjunto como protección contra la imposición.

La narración abraza una temática ya dispuesta en LSL, con la diferencia sustancial de que la criminalidad acontextual de los bandoleros es replicada en SQP porque "tienen que construir su vida desde la disculpa de su subsistencia, 73." Aparece de nuevo el zoomorfismo, pero como recurso de supervivencia en la montaña, en el sentido de que "a la montaña, además de conocerla, para hacerse con ella, hay que amarla. Sólo amando u odiando se tiene éxito en la acción, 40”, esquivando al enemigo, antes que combatiéndolo. Se interioriza el silencio como recurso primordial para sobrevivir, ya que "alguien desde las sombras le enviaba fuera de la historia, 27", rastreado en "páramos a la caza de los guerrilleros rojos, I39".

O’Donoghue (20I4) considera, en cambio, que en Luna de lobos, de Julio Llamazares, la naturaleza es enemiga del hombre, fuerza hostil que embrutece a los protagonistas. La sierra en SQP es amiga, uno de los personajes-escenario centrales de la narración. Esa naturalización obligada se focaliza frecuentemente como animalización, astucia, hipersensitividad:

En su vagar permanente, sin refugio ni campamento fijos, aguzó los instintos al máximo. Y llegó a comportarse como los animales en libertad. [...] Montes se transformó. Acabó siendo todo sentidos y, sobre todo, puro instinto. Un animal en toda regla. «Nada como volver al origen», se justificó en cierta ocasión al darse cuenta de su forma de actuar, tan propia de una fiera, [...] Los maquis se habían convertido en humo. A sus oídos, por los pueblos que atravesaba haciéndose pasar por mendigo o peregrino, no llegaba comentario. Todo era silencio [...] Montes [...] deambuló como los perros apestados en los que todo el mundo se ceba [...] lo apedreaban. No querían líos. Detrás de un desarrapado podía salir un maquis o la mismísima guardia civil, r3o-I30.

El propósito era "quedar al abrigo de la inmensidad de la naturaleza II5", "aprender a vivir, a servirse de la naturaleza, a combatir y, ante todo, a sobrevivir. Es decir, tiene que convertirse en maquis, 88", porque "es mejor el monte que la muerte, la lucha que la tortura I2I", pero siempre buscando el resquicio para la humanidad, cuando "al caer la noche, recordar en grupo era una costumbre impuesta para aliviar aquel existir a salto de mata que llevaban como guerrilleros, Io6", "que acaban con el papel de la verdad, que aquieta más que mil mentiras [...] Mejor molestar con la verdad que complacer con la lisonja, I85."

\footnotetext{
${ }^{\text {I8 }}$ Maffesoli (I987) insiste en el poder del silencio, interpretado por los grandes místicos como la forma por excelencia de la comunicación. Cfr. por otro lado desde la teoria de la comunicación y la pragmática la valoración de Mateu Serra (2OOI) sobre el papel del silencio.
} 
El ser-(del)-monte como obligada invisibilidad guerrillera es contradictorio con la necesaria visibilidad de lo político: "Nada como hacer ruido para consignar que uno existe [...] Les ha pedido que en la montaña se comporten como animales salvajes. [...] Vista, oído y olfato como animales. Y sobre todo, conciencia de grupo [...] Amar la montaña es formar parte de su paisaje, 48-50." Por ello, se tiene la sensación de que el gran protagonista coral es la naturaleza, el monte en este caso, que "lo transformaba en un gigante, 58 ".

Los gentilicios políticos coinciden en ambas narraciones, si tenemos en cuenta que los actores principales de la historia son parecidos, pero mucho más enriquecidos por un contexto social, que en SQP explica los resortes político-emocionales de los combatientes, más ambientado en el laberinto natural y social al que se ven abocados los guerrilleros que entraron en I944 por el Valle de Arán para derrocar a Franco. Es claro igualmente que el punto de vista del amigo-enemigo cambia; el enemigo es el franquismo amplio, ese apoliticismo de conformidad resignada contra el que chocan los guerrilleros, que en su semanario de 1944 Reconquista de España llaman a la «Insurrección nacional». (Ser guerrillero es un deber. Patriota, incorpórate a los guerrilleros), SQP, 65." Luchar contra el agresor externo (recuérdense las tropas moras de Franco y el papel de los militares africanistas que llegaron al puerto de Cádiz en julio de 1936), entrañaba fijar el significado de patriota como partidario republicano, bien distinta de la identidad que les concedía la dictadura de "rojos, republicanos, desafectos, gente de poco fiar para la Nueva España de Franco, 69.”

$\mathrm{Al}$ calor de las designaciones políticas de bandolero, forajidos, bandido, salteador, etc., SQP acepta estos nombres grupales destacando lo positivo del bandolero: "Si en los periódicos se infama a los resistentes [...], bautizándolos como bandoleros y criminales [...], al menos, llevar con hombría ese motejar injusto. Robin Hood, Pedro de Machuca, el Corrientes..., y los muchachos del maquis, todos en el mismo saco. Robar al fuerte para ayudar al débil. Ser modelo de justicia, ése es el detalle, 7I.”

Escrito ya en el siglo XXI, el relato gana en interés lector al sustituir los límites del combate de fuego por otro de la nebulosa de la memoria, vaporizada entre olvidos, determinantes para abrir los ojos ante el vacío posterior, velado por recuerdos y evocaciones, pues "el olvido como terapia puede ser más fuerte que el deseo de venganza, 7o", amnesia programada desde su ambigüedad constitutiva como herramienta de la supervivencia, porque "la mentira, cuando sirve de medicina, no es mentira, es alimento, IOI": "A fuerza de repetir sus mentiras, éstas se revestían con la cara de la verdad, 75 ", porque quienes entraron a España por los Pirineos encontraron a "hombres no aptos para la guerrilla. Gente vencida [...] Seres que, pese a todo, preferían el olvido y el sufrimiento [...] derrotados, abatidos, pisados y rotos, IIO-III."

SQP se convierte por momentos en crónica de la derrota, aún de la posderrota, con retiradas sinuosas, cuando "todo estaba perdido y todos estaban condenados. Solo quedaba la derrota. Y, posiblemente, el olvido, I 43 ”, porque 
"la gente quería olvidar, olvidarse, echar tierra y cal sobre los muertos, encarar el futuro con o sin amaneceres, con o sin montañas nevadas. [...] Interesaba el descanso y el silencio -la paz de la victoria, en palabras de vencedores-. El pasado era pasado y lo mejor para todos arrinconarlo e, incluso, si así se veía necesario, negarlo. [...] Hay algo mejor que el odio o la venganza, que nos dejen vivir, I64-I66."

Pero, finalmente, los guerrilleros dan digna sepultura a Montes, guerrillero,

\begin{abstract}
“vencido y sin memoria, te hemos recuperado. Vivirás por fin en el recuerdo, presente en este lugar concreto. Aquí estarás con todos nosotros [...] otros como tú saldrán a la luz de los pozos del olvido. No lo dudes, las fosas anónimas, los enterramientos en masa cubiertos por la cal y los osarios perdidos en las cunetas acabarán por tener su hora triunfal. El olvido y la ignominia han sufrido su primera derrota, I89”,
\end{abstract}

momento comprometedor porque "la memoria por sí sola no sirve -meditó-. La memoria es la selva en la que los recuerdos se extravían. Y se pierden, I95”, cuando pasados los años "los mayores tienden a hablar como si deseasen que quien les escucha está obligado a resolver sus acertijos. Así se comportaban Luisa y su madre cuando él realizaba algunas preguntas en torno a la guerra o al exilio, I77."

De paso, las exigencias comunicativas que fundaron esa memoria señalan los montes franceses, le maquis, luego olvidados, ya que "Leclerc [...] no daba crédito cuando descubrió que Críspulo, como la mayoría de su ejército de la Grand Combe, pertenecía a los rojos españoles quienes salvo Críspulo, chapurreaban un francés ininteligible. Por eso, la «grandeza» franca de De Gaulle les hacía reír, 75”, recuerdo novelado del embrión de ese primer olvido.

Esos encadenamientos de la memoria se sirven de la foto fija de las paremias, que "en la época del maquis contra los alemanes, cuando era necesario matar el tiempo [...] se enredaban en un ensartado de refranes contra otros contrincantes. A veces, era digna de ver la batalla verbal de refrán tras refrán. O mejor, de refrán contra refrán. [...] Era como vivir en España por un par de horas, 76 -77", aunque ya se sabe que eran excepciones del sigilo básico, pues las condiciones que debe reunir un buen guerrillero pasan por una serie de competencias verbales, cuales ser obediente y disciplinado, no discutir inútilmente, expresarse en tono bajo y comedido, vigilando que los demás hagan lo mismo, abstenerse de hacer comentarios que susciten sospechas, no revelar noticias, no criticar a ningún compañero, reprender a quien lo haga, memorizar recorridos, dar cuenta al jefe de situaciones importantes, guardar absoluto silencio en las marchas o transmitir todas estas obligaciones a los nuevos compañeros (Vidal Sales ([2002]/20o6: 6o-6I). Es decir, se compactaba al grupo, arma temible que podía desestabilizar las opresiones más sólidas (Maffesoli, I987).

Otro tema de SQP es la parálisis que produce el miedo: "vencido ante un enemigo invisible [...] su cobarde inmovilidad, su sumisión al dios del Partido, 26”, muy especial- 
mente porque uno de los párrafos centrales de la novela narra la inesperada decepción frente a los presos de Franco, maduros ya para ese apoliticismo práctico, pues

\begin{abstract}
"atemorizados, escapan del lugar, corriendo como locos, sin hacer caso a las palabras de los guerrilleros. Ni el alto amigos, ni el somos vuestros liberadores, ni camaradas y compañeros, ni viva la república, ni abajo los tiranos... sirven de nada. Todos escapan, pasando incluso entre las piernas de los guerrilleros que quieren detenerlos. Una estampida que arrasa con todo cuanto se le pone delante. [...] La mayoría se encierra en sus barracones. Han creído que era una prueba de la policía o de los falangistas [...] la gente tiene miedo de mostrar lo que piensa, 79.”
\end{abstract}

Referencia que continúa después, omnipresente en trabajos historiográficos y literarios sobre resistencia antifranquista: "Como siempre, a los nuestros, a los que mantenían el espíritu de la República, les colgaban la etiqueta de bandidos, malhechores o, incluso, de asesinos, I84-I85”, entrelazada con las reminiscencias bíblicas de David contra Goliat, dado que "en el mundo común de los hechos, los malos no son castigados y los buenos recompensados. El éxito se lo llevan los fuertes y el fracaso los vencidos, 93”, argumento que recoge Alba Rico (2007: 33) porque precisamente entendemos la victoria de David sobre Goliat como la victoria del débil sobre el fuerte, cuando realmente es justo al revés, la victoria de la fuerza tecnológica sobre la debilidad bruta, lo que suele obligar a que el relato del vencedor identifique victoria con justicia y derrota con mal.

\title{
4- Balance
}

El análisis de las dos novelas confronta dos modelos, en SQP de heteroglosia interna, plural, no hegemónica, reflexiva, deliberativa y de homoglosia en LSL, institucional, autoritativa, con intención de univocidad incontestable de contenidos fundamentales, programados internamente en el uso discursivo.

El autor de LSL sabía del poder de narrar mediante una ficción veraz que pretendía depositar un grado suficiente de verdad para aplaudir y todavía ensalzar las acciones de las contrapartidas (y similares) como propuesta impura que dejase impoluta la supremacía franquista. Con ese planteamiento narrativo quedó preparada para trazar un antagonismo en tal grado que el enemigo era criminal, desorganizado, instintivo, depravado y amoral, proponiendo el contrapeso ejemplar y situacional de la Guardia Civil, no solo para vencer, sino también para relatar y asentar su representación, la de la victoria como control narrativo clasificador de lealtades.

Como elemento primordial se ha examinado la variación gentilicia, que pone de relieve el caleidoscopio lector, que acerca o aleja, perfilando siempre nuevos matices y significados. De cualquier modo, la pluralidad de la guerrilla o de la resistencia antifranquista solo ha podido rozarse en este trabajo; obsérvese cómo Marco, historiador 
atento, ha debido recategorizar las denominaciones colectivas (bandoleros sociales en 2006 y vecinos en armas en 20I2). Con todo, el tiempo mismo reanima los vocablos, que siendo los mismos, comienzan a indicar otros contenidos, acariciando otras connotaciones, según nuevas conveniencias sociohistóricas, como ansiaba el general Prieto $^{19}$ :

\begin{abstract}
"Perdone usted que yo les siga llamando bandoleros. Han sido muchos años de llamarlos así y no me acostumbro a otro nombre, pero usted puede llamarlos como quiera. [...] Sabían que yo no era un asesino, como otros. [...] Les tengo respeto y un recuerdo de agradecimiento a los maquis. En comparación con los terroristas de ETA de hoy, los bandoleros son mártires.”
\end{abstract}

Jaramillo Bedoya (2013) apunta que la jerga militar es símbolo de una comunidad de habla específica, una de cuyas características identitarias es el uso de un código especial, trasmitido a quien ingresa en el grupo. En el caso de LSL se pretende ampliar el grupo haciendo omnipresentes sus propias denominaciones para toda la comunidad social, ensanchando un mercado lingüístico que premia y rechaza determinados usos y comportamientos, precisados del discurso categórico de la verdad, sin dejar posibilidad -lo cual es ciertamente complicado- para la interpretación lectora propia.

En SQP el tiempo abatido muestra que toda indagación es un peregrinaje, porque la memoria viene del olvido; si la memoria no está en las personas, está en los montes, en las sierras, en los campos; no mienten, no olvidan, porque hay huellas enraizadas. Estamos ante un discurso interrogativo, dubitativo, brotado desde la supervivencia, en forma de evocaciones y reconstrucciones, muy modalizadas, invitando a la discrepancia frente a la representación que el autor hace del mundo.

Aparentemente parece extravagante pensar que hay una planificación del olvido con un incesante manantial bibliográfico de fácil acceso. Sin embargo, esa información misma no parece comunicar mucho, porque hay una población que, en general, poco quiere saber de estos temas, ya que entre otros procedimientos se le han apuntado hechos para enterrarlos en un indiscriminado marasmo informativo, que confecciona a la postre la utilidad del olvido. En la España actual hay relativa libertad de elaboración de códigos para las propuestas de la memoria, con sus consecuentes modalidades, pero el control del canal y sus modalidades de circulación y -sobre todo- el control de las modalidades de codificación-descodificación de los mensajes está en manos de unas élites que no renuncian al olvido como regulación de un perpetuo ajuste de cuentas válido para su prosperidad; por ello se ha dotado de potentes aparatos ideológicos de gran potencia disipativa, pues leen memoria como revancha y no como justicia, igualando olvido con absolución, su paz.

La curiositas scrutandi no ata bien con la libido dominandi. Hay un riesgo permanente de la memoria; desde la anorexia semántica fascista se ha querido imponer un uni-

\footnotetext{
${ }^{\text {I9 }}$ Domingo (2002) le dedica un apartado, Manuel Prieto López: hubo «otra» Guardia Civil, pp. 312-323.
} 
verso en blanco y negro, susurrado, silenciado, acallado por la fuerza y por la rentabilidad de la obediencia mediante el miedo, delineado desde la pretensión isomórfica en LSL de la literatura con lo real. En cambio, en SQP ruge con toda su potencia un magma de significaciones que va de la coerción a la destrucción: la dictadura destruía, pero no seducía. En la inversión simbólica y comunicativa que tuvo que programar apostó por una identidad romántica (amigo-enemigo) frente a una identidad barroca (el superviviente sinuoso). La literatura pone de relieve, aún desde la ficción, una manera de entender el pasado desde el presente y, por lo tanto, una intención de no olvidar, aunque solo sea por vérselas con la derrota como única prueba de la justicia. SQP propone un caos y LSL un destino, pero -como en la Odisea- el placer del texto es bastidor y urdimbre de la memoria. 


\section{5 - Referencias Bibliográficas}

- Acín Fanlo, R. (2005). Siempre quedará París. Sevilla: Algaida.

- Álvarez Barrientos, J. y P. García Mouton (I986). Bandolero y bandido: Ensayo de interpretación. Revista de Dialectología y Tradiciones Populares, 4I, pp. 7-58.

- Aróstegui, J. (2004). Retos de la memoria y trabajos de la historia. Pasado y Memoria. Revista de Historia Contemporánea, 3, pp. 15-36.

- Aróstegui, J. y J. Marco (Coords.) (2008). El último frente: la resistencia armada antifranquista en España, 1939-1952. Madrid: Los Libros de la Catarata.

- Arroyo-Rodríguez, D. (20I0). Guerrilla Narratives in Spanish Contemporary Culture. Michigan: The University of Michigan.

- Bertrand de Muñoz, M. (i986). Bibliografía de la creación literaria sobre la Guerra civil española. Anales de la literatura española contemporánea. Society of Spanish and Spanish-American Studies, II, 3, pp. 357-4II.

- Bultheel, L. (2OI2). La representación del maquis en la novela española contemporánea. Un estudio comparativo de Luna de Lobos (1985) de Julio Llamazares y La noche de los Cuatro Caminos (2OOI) de Andrés Trapiello. Gent: Universiteit Gent.

- Cardinale, R. (2008). Imágenes del bandolero en algunas obras literarias españolas. Iberoamericana (2OOI-). Nueva época, Año 8, No. 3I, pp. I49-I63.

- Carvalho dos Reis, L. (2013). La voz dormida: o despertar de histórias silenciadas durante o franquismo. ReVeLe-Revista Virtual dos Estudantes de Letras, ${ }^{\circ} 5$.

- Chaves Palacios, J. (2003). Franquismo y oposición: propaganda contra el régimen en la década de los cuarenta. Historia Contemporánea 26, 2003, 353-368.

- Cruz Piñol, M. (i996). El nacimiento de la conciencia lingüística europea en una base de datos. En Martinell Gifre, E. y M. Cruz Piñol (Eds.) (1996). La conciencia lingüística en Europa. Testimonios de situaciones de convivencia de lenguas (ss. XII-XVIII). Barcelona: PPU, pp. $3^{\mathrm{I}-45}$.

- Domingo, A. (2002). El canto del búho. La vida en el monte de los guerrilleros antifranquistas. Madrid: Oberon-Anaya.

- Fairclough, N. (2000). Representaciones del cambio en el discurso neoliberal. Cuaderno de Relaciones Laborales, I6, pp. I3-35. 
- Faix, D. (2009). La guerra civil y la posguerra a través del espacio narrativo. Análisis de Si te dicen que caí de Juan Marsé. ÉTUDES ROMANES DE BRNO, 3O, 2.

- Fatás Cebollada, J. (2008). Importancia de la acción como recurso novelístico en Siempre nos quedará París, de Ramón Acín”. En Acín, R. e I. Sancho (Coords.) (2008). Invitación a la lectura: Curso 2007-2008, pp. 9-I9.

- Faye,J. P. ([1972]/1974). Los lenguajes totalitarios. Madrid: Taurus. Vers. esp. de M. Á. Abad.

- Fowler, R. (I988). La literatura como discurso social. La práctica de la crítica lingüística, Alicante: Marfil. Trad. de M. F. Rodríguez Álvarez.

- Fowler, R., B. Hodge, G. Kress y T. Trew ([1979]I983). Lenguaje y Control. México: Fondo de Cultura Económica. Trad. de Valente Reyes.

- Fuentes González, A. D. (20I5). Gente de la sierra, maquis, guerrilleros, bandoleros...: Sociolingüística gentilicia para el tiempo abatido. En Tonos digital: Revista electrónica de estudios filológicos, (28), 24 .

- Fuentes González, A. D. (2OI5a). Lectura sociolingüística. En Martos Núñez, Eloy, y Campos Fernández-Fígares, Mar (Eds.) (2OI5). Diccionario de nuevas formas de lectura y escritura. Madrid: RIUL-Santillana, $2^{\text {a }}$ edic. en CD, 2OI5, pp. 457-459.

- García Marcos, F. (I999). Fundamentos críticos de sociolingüústica. Almería: Universidad de Almería.

- Gaspar Celaya, D. (2012). De la memoria a la historia. Un estado de la cuestión sobre la participación española en la resistencia. Cahiers de civilisation espagnole contemporaine, 9. Obtenido el 26 de noviembre de 20I4 desde http://ccec.revues.org/ 4273 .

- Hall, S. (1997). El trabajo de la representación. En S. Hall, (Coord.) (1997). Representation: Cultural Representations and signifying practices, London, Sage Publications, Cap. I, pp. I3-74. Trad. de E. Sevilla Casas.

- Heine, H. y J. M. Azuaga (2005). Laoposición al franquismo en Andalucía Oriental. Madrid: Fundación Salvador Seguí.

- Hobsbawm, E. (1998). Sobre La Historia, Capítulo XXI, Crítica: Grijalbo Mondadori, Barcelona, I998, pp. 266-276. Obtenido el 22 de julio de 2 IO4 desde www.cholonautas.edu.pe / Biblioteca Virtual de Ciencias Sociales.

- Izquierdo, J. M. (200I). Memoria y literatura en la narrativa española contemporánea: unos ejemplos. Anales, $\mathrm{n}^{\circ}$ 3-4, 2OOO-2OOI (Ejemplar dedicado a: Historia y memoria), pp. IOI-I28. 
- Izquierdo, J. M. (2002). Maquis: Guerrilla antifranquista. Un tema en la literatura de la memoria española. Romansk fórum, I6, 2, pp. IO5-ІІ6.

- Jaramillo Bedoya, J. I. (20I3). Aspectos sociolingüísticos de la jerga en el ejército de Colombia. Universidad Tecnológica de Pereira. Trabajo de Grado.

- Jiménez Cano, J. M. (2003). Claves textuales, pragmáticas y sociolingüísticas para el comentario de textos. Tonos digital: Revista electrónica de estudios filológicos, 6, r. Obtenido el I de noviembre de 2OI4 desde http:/ / www.um.es/tonosdigital/znum6.

- Juliá, S. (2009). Los nombres de una guerra. Revista de historia Jerónimo Zurita, 84. Rodrigo, J. y Ruiz Carnicer, M. Á. (Coords.) (20o9). Dossier: Guerra Civil: las representaciones de

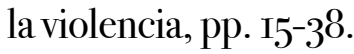

- Lambert, J., R. Meylaerts y M. Borden (2005). La lengua de la literatura: la institucionalización por la mediación del discurso. Tonos Digital, 9. Obtenido el r6 de junio de $20 \mathrm{O} 2$ desde www.um.es/tonosdigital/znumg/estudios/lengualiteratura.htm.

- Luengo, A. e I. Cuñado (2007). La encrucijada de la memoria. La memoria colectiva de la Guerra Civil Española en la novela contemporánea. Revista Canadiense de Estudios Hispáni$\cos , 3{ }^{\mathrm{I}}(3)$, pp. 536-537.

- Maffesoli, M. (1987). La hipótesis de la centralidad subterránea. Revista de Occidente, 73, pp. $63-74$.

- Marco, J. (2006). “Guerrilla, bandolerismo social, acción colectiva. Algunas reflexiones metodológicas sobre la resistencia armada antifranquista”, en Cuadernos de historia contemporánea, 28, págs. 28I-3OI.

- Marco, J. (2OII). Ecos partisanos. La memoria de la resistencia como memoria conflictiva. Historia del presente, I7, I, $2^{\text {a }}$ época, pp. 79-9I.

- Marco, J. (2012). Guerrilleros y vecinos en armas. Identidades y culturas de la resistencia antifranquista. Granada: Comares.

- Mateu Serra, R. (200I). El lugar del silencio en el proceso de comunicación. Lleida: Universitat de Lleida. Tesis doctoral.

- Morant, R. (2OI4). La discriminación onomástica en la vida cotidiana. RIVISTA ITALIANA diONOMASTICA. RION, XX (2014), 2, pp. 685-698.

- Moreno-Nuño, Carmen (20I2). Criminalizing Maquis: Configurations of Anti-Francoist Guerrilla Fighters as Bandoleros and Bandits in Cultural Discourse. En Antonio Gómez Ló- 
pez-Quiñones y Carmen Moreno-Nuño (Eds.) Armed Resistance: Cultural Representations of the Anti-Francoist Guerrilla. Hispanic Issues On Line (Fall 20I2): 79-99. Web.

- Moreno Gómez, J. B. y J. A. Romero Navas (2012). Bibliografía de Guerrilla. Publicaciones sobre el fenómeno del maquis antifranquista. Tiempo de cerezas ediciones.

- Núñez Seixas, X. M. (2005). Los vencedores vencidos: la peculiar memoria de la División Azul, 1945-2005. Pasado y Memoria. Revista de Historia Contemporánea, 4, pp. 83-II3.

- O’Donoghue, S. J. R. (2OI4). Nature as enemy of man in Julio Llamazares's Luna de lobos. En Forum for Modern Language Studies. Oxford University Press.

- Ortiz Mateos, A. (20I3). La guerrilla y la radio. El papel de Radio España Independiente en el movimiento guerrillero español (194I-1952). Espacio, tiempo y Forma, Serie V, Historia Contemporánea, 25, págs. 327-340.

- Pêcheux, M. ([1982]I990). Delimitações, inversões, deslocamentos. Cadernos de Estudos lingüísticos, Campinas, I9, pp. 7-24.

- Perea Delgado, L. M. (20I2). Los de la Sierra, presencia de la guerrilla antifranquista en los montes de Tarifa. AlQantir, I2, pp. I84-I97.

- Pérez Serrano, J. (2004). Experiencia histórica y construcción social de las memorias. La transición española a la democracia. Pasado y Memoria. Revista de Historia Contemporánea, 3, 2004, pp. 93-122.

- Potok, M. (2OI2). Estrategias literarias para la recuperación de la memoria histórica. La narrativa actual frente a la Guerra Civil. Études romanes de Brno, 33, 2, pp. 9-20.

- Preti, D. (1975). Sociolingüística: os níveis de fala. Um estudo sociolingüústico do diálogo na literatura brasileira. São Paulo: Companhia Editora Nacional.

- Querol Sanz, J. M. (20IO). El otro magrebí en la literatura española. En M. Iglesias Santos (Coord.) (2OIO). Imágenes del otro: identidad e inmigración en la literatura y el cine. Biblioteca Nueva, pp. 63-86.

- Rossi-Landi, F. (1970). El lenguaje como trabajo y como mercado. Caracas: Monte Ávila.

- Ruiz Ayúcar, Á. ([1953]ı98I). La sierra en llamas. Madrid: Fuerza Nueva.

- Ruiz Sánchez, A. (2007). La memoria literaria de la emigración: el surgimiento de los primeros textos de origen español (ı964-I989). Iberoamericana, VII, 26, págs. I67-I79. 
- Sánchez Cervelló, J. (Ed.) (2003). Maquis: el puño que golpeó el franquismo. Barcelona: Flor del Viento.

- Sánchez Zapatero, J. (20Iо). La cultura de la memoria. Pliegos de Yuste, II-I2, pp. 26-30.

- Sánchez Zapatero, J. (2OII). La representación de la guerrilla antifranquista en Inés y la alegría y Donde nadie te encuentre. Analecta malacitana: Revista de la Sección de Filología de la Facultad de Filosofía y Letras, $34(2), 55^{\mathrm{I}-567}$.

- Schmitt, C. (I963). Teoría del guerrillero. Obtenido el 26 de febrero de 2014 desde http:// es.scribd.com/doc/86403шI/Carl-Schmitt-Teoria-del-Guerrillero.

- Schmitt, C. ([1987]2009). El concepto de lo político. Texto de 1932 con un prólogo y tres corolarios. Vers. de R. Agapito. Madrid: Alianza.

- Tyras, G. (2007). Memoria y resistencia: el maquis literario de Alfons Cervera. Madrid: Montesinos.

- Vidal Sales, J. A. ([2002]/2006). Maquis. La verdad histórica de la "otra Guerra". Madrid: Espasa.

- Voloshinov, V. ([I929]I992). El marxismo y la filosofía del lenguaje. Madrid: Alianza. Trad. de Tatiana Bubnova.

- Winter, U. (2006). Lugares de memoria de la Guerra Civil y el franquismo: representaciones literarias y visuales. Iberoamericana-Vervuert.

- Yusta, M. (2002). La resistencia armada contra el régimen de Franco en Aragón (1940-1952). Zaragoza: Universidad de Zaragoza. 